\title{
MEGASISTIS VE ARTMIŞ NUKAL TRANSLUSENSİ İLE PREZENTE OLAN TRİZOMI 18: OLGU SUNUMU
}

\section{TRISOMY 18 PRESENTING WITH MEGACYSTIS AND INCREASED NUCHAL TRANSLUCENCY: A CASE REPORT}

\author{
Önder SAKİN*, Bülent KARS**, Cenk DEMİ**, Ömer Talip TURHAN*, \\ Doğan VATANSEVER*
}

\section{ÖZET}

Amaç: Bu vaka sunumunun amacı erken gebelik haftasında saptanan fetal megasistis ve artmış nukal translusensi ile birliktelik gösteren trizomi 18 olgusunu sunmaktır.

Olgu: Hastanın birinci trimester ultrasonografik taramasında fetal longitudinal mesane çapı 19mm, nukal translusensi ise $5 \mathrm{~mm}$ olarak ölçüldü. Ductus venozus doppler incelemesinde patolojik ters "a” dalgası tespit edildi. Hastaya 16. gebelik haftasında amniosentez yapıldı. Fetal karyotipleme sonucu trizomi 18 olarak saptandı. Gebelik ailenin de isteğiyle sonlandırıld1.

Sonuç: Fetal megasistis ve artmış nukal translusensinin kromozom anomalileri ile birliktelik olasılı̆̆ yükssek olduğundan fetal karyotip tayini yapılması gerekliliğini belirtmek istedik.

Anahtar kelimeler: megasistis; trizomi 18; nukal kalınlık ölçümü

\begin{abstract}
Object: The purpose of this case report is to present a case of trisomy 18 diagnosed prenatally in early gestation due to ultrasonographic findings of megacystis and increased nuchal translucency.

Case: In the patient's first trimester ultrasound scan, fetal longitudinal bladder diameter was 19 mm and the nuchal translucency was $5 \mathrm{~mm}$. Aditionally on ductus venosus doppler study there was pathologic inverted 'a' wave. At 16th week of gestation amniocentesis was performed. The result of fetal karyotyping was Trisomy 18. Pregnancy was terminated with the approval of the family.

Conclusion: We want to emphasize the necessity of fetal karyotyping in cases with increased nuchal translucency accompanying fetal megacystis since probability of chromosomal abnormalities is high.

Key words: megacystis; trisomy 18; nuchal translucency measurement
\end{abstract}

\section{GİRIŞ}

Fetal megasistis herhangi bir gestasyonel dönemde normal sınırlardan daha yüksek oranda genişlemiş mesane olarak tanımlanır. Birinci trimesterde (10-14. gebelik haftası) longitudinal mesane çapının $7 \mathrm{~mm}$ ve üzerinde olması fetal megasistis olarak tanımlanır (1). Megasistis görülen durumlarda obstrüktif üropati (üretral tıkanıklıklar, posterior üretral valv, üretral atrezi vb) olabileceği gibi genetik bir hastalı da olabilmektedir (2).

Nukal translusensi (NT) fetal boynun arkasında toplanan subkutan sıvı birikimidir. Pek çok krozmozomal defektte geniş bir fetal anomali ve genetik sendrom yelpazesinde 11-14 haftalar arasındaki yaygın fenotipik görünüm, NT kalınlığının artmasıdır (3). Megasistisli olgularda NT kalınlığı, kromozomal olarak anormal olanların \%75'inde normallerin ise yaklaşık \%30'unda artmıştır $(4,5)$.

$\mathrm{Bu}$ vaka sunumunun amaci; erken gebelik haftasında saptanan fetal megasistis ve artmış nukal translusensi ile birliktelik gösteren trizomi 18 olgusunu literatür eşliğinde tartışmaktır.

OLGU:

11-14 hafta tarama testi yaptırmak üzere kliniğimiz perinatoloji polikliniğine başvuran 12 haftalık gebede

Date received/Dergiye geldiği tarih: 17.05.2015- Date accepted/Dergiye kabul edildiği tarih: 11.12.2015

* İstanbul Dr. Lütfi Kırdar Kartal Eğitim ve Araştırma Hastanesi, Kadın Hastalıkları ve Doğum Kliniği,

** Özel Dragos Gülen Tıp Merkezi, İstanbul, TÜRKIYY

(Corresponding author/İletişim kurulacak yazar: sakin-onder@hotmail.com) 
yapılan USG'de; CRL53.2 mm (12 hafta +3 gün), nukal translusensi $5 \mathrm{~mm}$ mesane longitudinal çap1 $19 \mathrm{~mm}$, bulunmuştur (Resim 1, 2). Duktus venözus doppler incelemesinde patolojik ters "a" dalgası tespit edilmiştir (Resim 3). Hasta ikili testini yaptırmamış ve 16 . gebelik haftasında kontrole gelmiștir. Hastaya ve ailesine mevcut durumun devam ettiği ve kesin tanı için ileri tetkik yapılması gerekliliği anlatılmıştır. Hastaya 16. gebelik haftasında yapılan amniosentez sonucu trizomi 18 ile uyumlu gelmişve gebeliğk ailenin rızası alındıktan sonra sonlandırılmıştır.

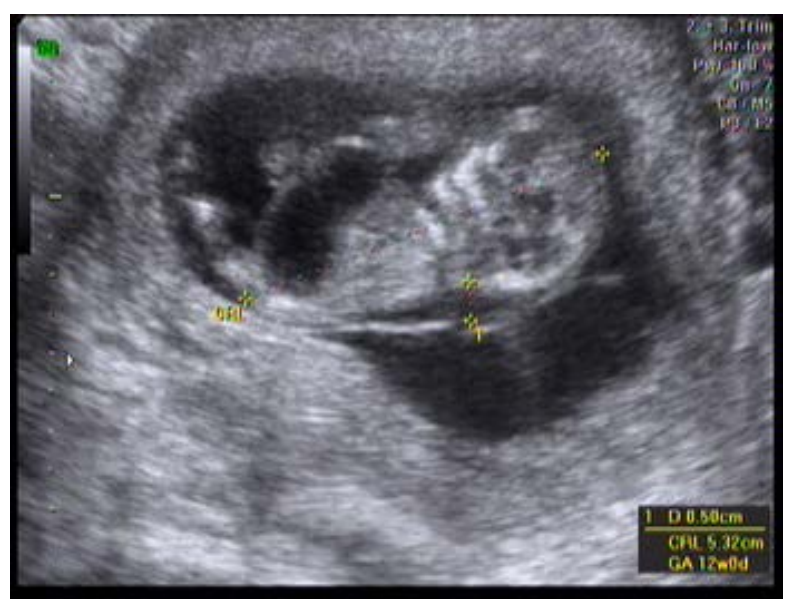

Resim 1: Megasistis görüntüsü

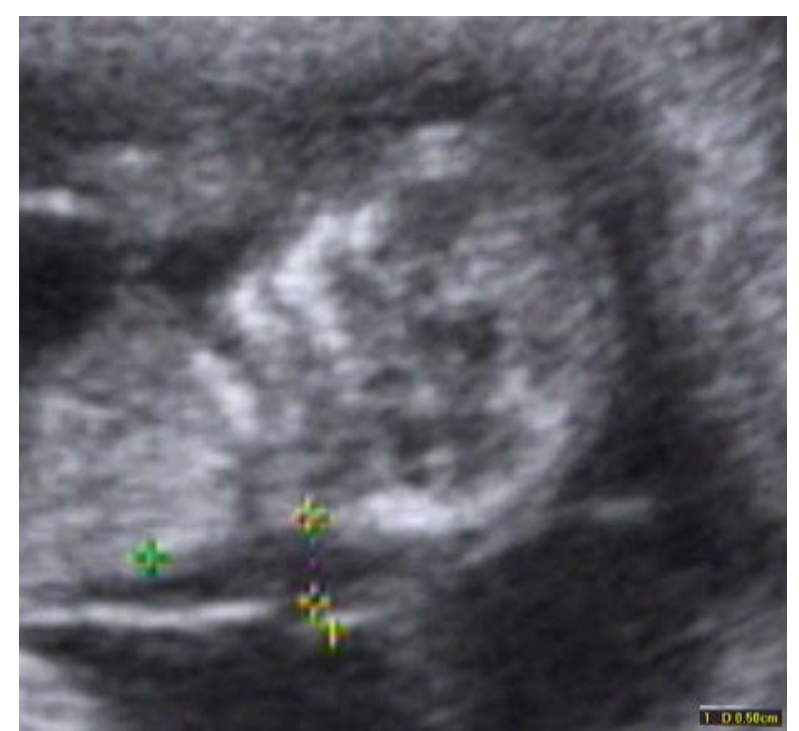

Resim 2: Artmış ense kalınlığı görüntüsü

\section{TARTIŞMA:}

Megasistis; mesane longtidunal çapının geniş izlenmesi ile saptanan aşırı dilatasyon durumudur. Ultrasonda; karın alt bölgesinde, orta hatta, içi sıvı ile dolu, anekoik, düzgün sınırlı, küresel bir yapı şeklinde izlenmektedir. Mesane çap 1 1. trimesterde $7 \mathrm{~mm}$ ve altındadır. 8-11 $\mathrm{mm}$ arası hafif veya grade 1 dilatasyon kabul edilir. 12$15 \mathrm{~mm}$ arası orta veya grade $2 ; 15 \mathrm{~mm}$ üzeri ise ciddi veya grade 3 olarak kabul edilir (5). Bizim karşılaştığımız vakada mesane çapı $19 \mathrm{~mm}$ olarak belirlenmiştir ve megasistis tanısı konulmuştur.
Megasistis görülme sıklığı Sebire ve ark.'nın araştırmasında 24,492 gebede yapılan tarama sonucunda 15 vaka olarak bulunmuş ve 1633 gebede $1(\% 0,06)$ olarak belirtilmiştir (5).

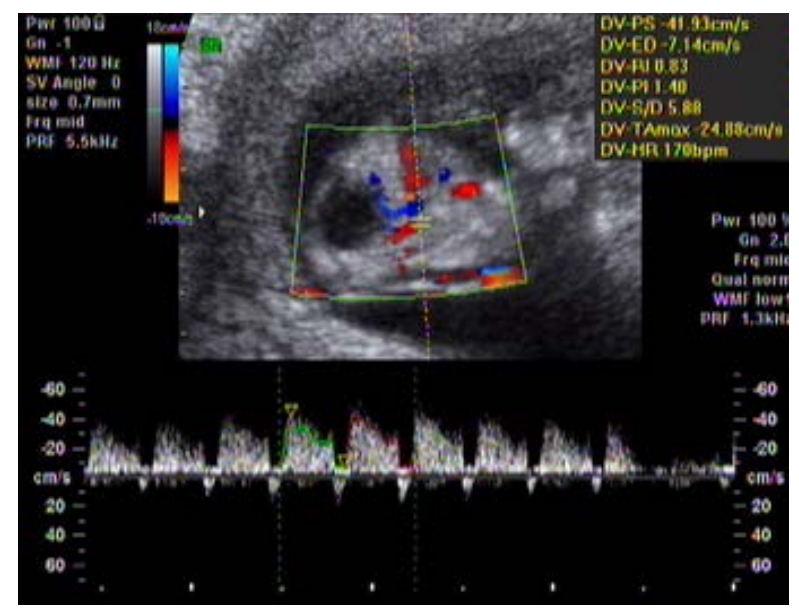

Resim 3: Duktus venozusda ters A dalgası görüntüsü

Megasististe obstrüktif üropati (posterior üretral valv, üretral atrezi gibi) olabileceği gibi artmış nukal translüsensi olgularında genetik bir hastalık olabileceği de bildirilmektedir. Megasistisli olgularda ense kalınlığı, kromozomal olarak anormal olanların \%75'inde, normallerin ise yaklaşık \%30'unda artmıştır $(4,5)$.

Fetal anomali prevalansı ve gebelik prognozunun kötü olma ihtimali NT kalınlığına paralel olarak artar. NT

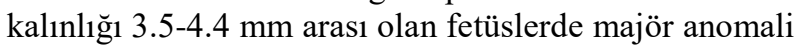
olma şansı \%10 iken 4.5-5.4 mm arasında bu oran \%50'ye kadar yükselmektedir. Bizim hastamızda yapılan ölçümde NT 5 mm olarak saptanmıştır (6).

Megasistis birçok kromozom anomalisine de eşlik edebilmektedir. Şu ana kadar bildirilen tüm çalışmaların sonucunda; trizomi 13 , trizomi 18 , trizomi 21 , trizomi 4 , mozaik trizomi 15, dengesiz translokasyonlar, 14 ve 20 . kromozomlarda dengesiz translokasyon, triploidi $(69, X X Y)$ ve $46, X X / 45, X$ mozaisizm tanıları konulmuştur. Kromozom anomalisi oranının \%20 ila $\% 50$ arasında değiştiği belirlenmiştir. Bizim hastamızda da yapilan amniosentez sonucunda trizomi 18 saptanmıştır $(1,6)$.

Fievet L ve ark. (2014) megasistis saptanan 69 vakayı retrospektif olarak incelemiş, 26 vaka birinci trimesterde, 21 vaka ikinci ve 22 vaka ise üçüncü trimesterde saptanmıştır. Üçüncü trimesterde saptanan 22 vakadan 20 tanesinde canlı doğum gerçekleşmiş, ancak birinci trimesterde saptanan 26 vakadan sadece 4 ü canlı doğumla sonlanmıştır. Tanıdaki gestasyonel yaşın prognozdaki önemi vurgulanmıştır (7).

Liao ve ark.'nın (2003) yaptıkları 166 megasistis vakasının değerlendirilmesi sonucunda; 76 sında gebelik (\%46) sonlandırılmış, 6 sı takipler esnasında kaybedilmiş (\%4), 13 ünde fetüs 20. haftadan önce düşükle kaybedilmiş (\%8) ve 71 tanesi sağlıklı canlı doğum ile sonuçlanan spontan gerileme göstermiştir (\%43). 30 vakada kromozom anomalisi olduğu belirlenmiştir. Bunlar arasında 17 trizomi 13, 7 trizomi 
18, 2 trizomi 21, 1 trizomi 4, 1 mozaik trizomi 15,1 dengesiz translokasyon ve 1 triploidi saptanmıştır (4).

Yine bu çalışmada mesane çapı 7-15 mm arasında olanlarda kromozom anomalisi riski \%25 civarında iken $15 \mathrm{~mm}$ üzerinde olanlarda bu riskin \%10'lara düştüğü belirlenmiştir. Kromozom anomali riski düşük olan gruptakilerin progresif obstrüktif uropati ile ilişkili olduğu ifade edilmiştir (4). Bizim vakamızda da mesane çap1 $19 \mathrm{~mm}$ ölçülerek kromozom anomali riski daha düşük olan grupta olmasına rağmen trizomi 18 olduğu saptanmıştır.

Duktus venosus, umblikal venle gelen oksijenlenmiş kan akımını inferior vena kava ve atrium yoluyla foramen ovale'ye yönlendirir. Bu damar kardiak fonksiyonu değerlendirmede yararlanılan en kullanışlı damardır. Kalp yetersizliğinde, kardiak anomali olsun veya olmasın duktusta "A" dalgası kaybı veya ters akım görülür. 11-14 haftalarda nukal translusenside artış saptanan fetuslarda duktal akımı inceleyen bir çalışmada kromozomal anomalili 63 fetusun 57'sinde (\%90.5), normal kromozomlu 423 fetusun ise sadece 13'ünde (\%3.1), atrial kontraksiyon sırasında akım kaybı yada ters akım olduğu bildirilmiştir (6). Bizim hastamızda 12. haftada yapılan ultrasonda ters a dalgası görülmüş, fetüsde kromozomal bir anomalinin çıkacağı olasılığını güçlendirmiştir.

Megasististe erken dönemde saptananların prognozu kötüdür. Tedavi seçeneklerinin değerlendirildiği araştırmalarda birkaç yöntem üzerinde durulmuştur. Bunlar veziko-amniotik şant, vezikosentez ve sistoskopik üretral valv ablasyonu işlemleridir. Vezikoamniotik şant tedavisinin obstrüktif patoloji düşünülen durumlarda uygun olabileceği belirtilmiştir. Ancak alınan başarısız sonuçlar nedeniyle henüz tedavi sınırları net olarak çizilemediği sonucuna ulaşılmıştır $(1,8)$.

Müller Brochut ve ark. 54 vakayı retrospektif olarak incelemiş, 39 izole megasistis vakasından 24 üne vezikosentez ve vezikoamniotik şant işlemlerinden biri uygulanmış ve araştırmalarının sonucunda prune belly sendromu olan megasistisli fetüsler çıkartıldıktan sonra iyi seçilerek erken dönemde tedavinin sonuçları iyileştirme potansiyeli olduğunu belirtmişlerdir (9).

Sonuç olarak veziko-amniotik şant tedavileri 1984'den bu yana denenmiştir. Amaç bypass yöntemi ile böbreklerin dekompansasyonunu sağlamak, renal displaziyi önlemek, amnion sıvı miktarını ayarlamak ve akciğer matürasyonu için yeterli sıvı sağlamaktır. Ancak bu çabaların şu ana kadar çarpıcı bir yarar sağladığı gösterilememiştir. Merz ve ark. şant tedavisinin bir terapötik seçenek olarak sunulmaması sonucuna varmışlardır. Ayrıca bu konuda aile ile görüşülürken bu işleme bağl1 potansiyel komplikasyonlardan damembranların rüptürü, prematür doğum ve koryoamnionit riskleri yer almaktadır- söz etmek gereklidir (10).

\section{SONUÇ:}

Kromozom yapısı normal olan çap 7-15 mm arasındaki vakalarda takipte \%90'inda spontan gerileme, \%10'unda ilerleme olduğu ve/veya ekojenik böbrek geliştiği gözlenmiştir. Ancak mesane çapı $15 \mathrm{~mm}$ üzerinde olanların hiçbirinde spontan gerileme olmadığı belirtilmiştir (4). Bu araştırmaya göre de bizim olgumuzda kromozom anomalisi bulunmamış olsa dahi spontan gerileme beklenilmemesi sonucu çıkmaktadır. Tüm bu bilgiler doğrultusunda; megasistis yüksek oranlarda yapisal ve kromozomal anomalilerle birliktelik gösteren bir durumdur.

$\mathrm{Bu}$ anomalinin saptandığı gebeliklerde detaylı fetal değerlendirme sonrasında koryon villus biopsisi veya amniosentez gibi işlemlerle karyotip tayininin yapılması önerilmektedir.

İncelemeler sonucunda saptanan bilgiler aile ile paylaşılmalı ve izole olanlarda dahi prognozun iyi olmadığı hakkında bilgi verilmelidir.

Kesin prognozu belirlemek ve prenatal tedavilerin sonuçlarını öngörmek henüz mümkün değildir. Ancak; megasistisin kaçıncı haftada saptandığı, genişlik derecesi, organik bir patolojinin eşlik edip etmediği, böbreklerin durumu, ilave malformasyon ve karyotip anomalisi olup olmadığına dikkat edilmelidir. Gebeliğin sonlandırılması kararını bu bilgiler eşliğinde aile ile paylaşmak doğru yaklaşım olacaktır.

\section{KAYNAKLAR:}

1. Boissier K, Varlet MN, Chauleur C, Cochin S, Clemenson A, Varlet F, Bellicard E, et al. Early fetal megacystis at first trimester: a six-year retrospective study. Gynecol Obstet Fertil. 2009;37(2):115-24.

2. Fievet L, Faure A, Coze S, Harper L, Panait N, Braunstein D ve ark. Fetal megacystis: etiologies, management, and outcome according to the trimester. Urology. 2014 Jul;84(1):185-90.

3. Nicolaides KH. Nuchal translucency and other firsttrimester sonographic markers of chromosomal abnormalities. Am J Obstet Gynecol. 2004;191(1):45-67.

4. Liao AW, Sebire NJ, Geerts L, Cicero S, Nicolaides KH. Megacystis at 10-14 weeks of gestation: chromosomal defects and outcome according to bladder length. Ultrasound Obstet Gynecol. 2003;21(4):338-41.

5. Sebire NJ, Von Kaisenberg C, Rubio C, Snijders RJ, Nicolaides KH. Fetal megacystis at 10-14 weeks of gestation. Ultrasound Obstet Gynecol. 1996;8(6):387-90.

6. Matias A, Gomes C, Flack N, Montenegro N, Nicolaides KH. Screening for chromosomal abnormalities at 10-14 weeks: the role of ductus venosus blood flow. Ultrasound Obstet Gynecol. 1998;12(6):380-4.

7. Fievet Let al. Fetal megacystis: etiologies, management, and outcome according to the trimester. Urology. 2014;84(1):185-90.

8. Bornes $\mathrm{M}$ et al. Outcome and etiologies of fetal megacystis according to the gestational age at diagnosis. Prenat Diagn. 2013;33(12):1162-6.

9. Müller Brochut AC et al. Fetal Megacystis: Experience of a Single Tertiary Center in Switzerland over 20 Years. Fetal Diagn Ther. 2014;36(3):215-22.

10. Eberhard Merz ve ark. Obstetrik ve jinekolojide ultrason. 2.bask1 cilt 1. Doğan Tip Kitapevi, 2002, 320-25. 